Railway Engineering

Jan. 2021

Issue:13, Page: 29-42

Research Article

doi: $10.47072 /$ demiryolu. 802565

http://dergipark.org.tr/demiryolu

e-ISSN: 2687-2463, ISSN: 2149-1607

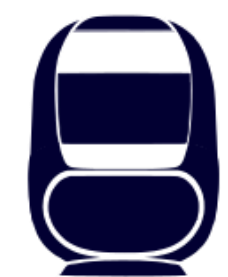

\title{
Demiryollarında Düzeltici Bakım Çalışmalarının Etkilerinin Standart Sapma Yöntemi ile Değerlendirilmesi
}

\author{
Polat YALINIZ*1®, Sezgin İÇA \\ ${ }^{1}$ Kütahya Dumlupınar Üniversitesi, Mühendislik Fakültesi, İnşaat Mühendisliği Bölümü, \\ Kütahya, Türkiye \\ ${ }^{2}$ Kütahya Să̆llk Bilimleri Üniversitesi, Yapı İşleri ve Teknik Daire Başkanlığı, Kütahya, \\ Türkiye \\ *polat.yaliniz@dpu.edu.tr
}

(Alınış/Received: 30.09.2020, Kabul/Accepted: 03.11.2020, Yayımlama/Published: 31.01.2021)

\begin{abstract}
Öz: Bu çalışmada, Kütahya-Afyonkarahisar şehirleri arasındaki konvansiyonel taşımacılık yapılan demiryolu hattı üzerinde belirli bir bölüm incelenmiştir. Belirtilen yol kesiminde; dever, ekartman, nivelman, fleş ve burulma yol geometrisi parametrelerine ait hatalar incelenerek ilgili EN 13848-5 standard1 çerçevesinde değerlendirilmeler yapılmıştır. Kütahya-Afyonkarahisar demiryolu hattı 2013 yılında poz çalışması yapılarak hat tamamen yenilenmiştir. Hattın kalitesindeki iyileşmeleri karşılaştırılma imkanı bulunan demiryolu hattında yol geometrisi ölçüm makineleri ile yaklaşık 11 yıllık zaman dilimi içerisinde ölçüm çalışmaları yapılmıştır. Bu ölçümler sayesinde yol kesimindeki bozulmalar, iyileşmeler, yapılan düzeltici bakım ve yol yenileme çalışmalarının etkileri EN 13848-5 standardında yer alan standart sapma yöntemi ile belirlenmiştir. Demiryollarında sahip olunan kısıtlı kaynak ve iş gücü nedeniyle bakım önceliklerinin belirlenmesi gerekmektedir. Bu nedenle, bu çalışma ile yol geometrisindeki bozulmalar ve iyileşmelerin değerlendirilmesinde hangi yol geometrisi parametrelerinin daha etkili olduğu ve bu etkilerin hız gruplarındaki değişimleri incelenerek, bakım kaynaklarının daha etkili kullanılması hedeflenmiştir. Fleş kusurları ile ilgili yapılacak düzeltici bakım çalışmalarının yolun genel kalitesinin artırılmasında düşük hız gruplarında daha etkili olduğuna ve yolun ilk kalitesinin yüksek olması ile yolun genel kalitesinin daha uzun süre korunabildiği sonuçlarına varılmıştır.
\end{abstract}

Anahtar kelimeler: Demiryolu, Fleş, Nivelman, Yol Geometrisi Kalitesi, Yol Geometrisi Kusurları

\section{Evaluation of the Effects of the Corrective Railway Maintenance Activities with the Standard Deviation Method}

\begin{abstract}
In this study, a specific part of the railway line between Kütahya and Afyonkarahisar cities have been investigated. At the stated track section, the defects of the track geometry parameters; cross level, track gauge, longitudinal level, twist and alignment have been studied and evaluated in accordance with the standard EN 13848-5. Kütahya-Afyonkarahisar railway line complete track renewal was performed in 2013. Having the opportunity to compare the improvement at the track geometry quality at the line, measurements were carried out on the track among 11 years period with the help of track geometry measurement vehicles. Degradations, improvements, the effects of the corrective maintenance and the track renewal activities were determined owing to measurements performed on the track, using the standard deviation method in the EN 13848-5 standard. Maintenance priorities need to be determined due to the limited resources and workforce at railways. Therefore, with this study, it is aimed to use maintenance resources more effectively by inspecting which track geometry parameters are more effective in evaluating the deteriorations and improvements in track geometry and the changes in speed groups of these effects. It has been concluded that the corrective maintenance activities to be carried out on the alignment defects of the track are more effective in increasing the overall quality of the track in low-speed groups and that the higher the initial quality of the track, the longer the overall quality of the track can be maintained.
\end{abstract}

Keywords: Railway, Alignment, Longitudinal Level, Track Geometry Quality, Track Geometry Defects 


\section{Giriş}

Dünyada son yıllarda ulaştırma alanında çok büyük yatırımlar yapılmakta olup demiryolu yatırımları bu alanda büyük paya sahiptir. Demiryollarında yeni yapılan dev bütçeli yatırımlar sayesinde yollar yüksek hızlı tren standartlarına uygun hale getirilmiştir fakat bundan daha önemlisi işletme, bakım ve güvenlik şartlarının sağlanıp yolun her koşul altında hizmet standartlarının korunmasıdır. Yol kalitesinin korunmasında ise en önemli unsur yol geometrisi kusurlarının sürekli olarak gözlem altında tutularak bakım faaliyetlerinin zamanında yapılmasıdır. Demiryolu hattının kontrol edilmesinde en önemli amaç yüksek düzeyde güvenliği sağlamak ve hat bileşenlerinden servis ömrü boyunca en iyi ekonomik verimi elde etmektir [1].

$\mathrm{Bu}$ çalışmada, söz konusu yol geometrisi kusurlarını, yoldaki bozulmaları incelemek, bozulma/iyileşme eğilimlerini belirlemek, bakım faaliyetlerinin ve poz çalışmasının yol geometrisi kalitesine etkilerini gözlemlemek üzere Kütahya - Afyonkarahisar demiryolu hattında belirli bir yol kesimi değerlendirilmiştir. TCDD 71. Yol Bakım Onarım Müdürlüğü sorumluluk sahasında yer alan konvansiyonel taşımacılık yapılan Kütahya - Afyonkarahisar illeri arasındaki demiryolunun Alayunt İstasyonu (Km 66+874) ve Çögürler İstasyonu $(\mathrm{Km} \mathrm{86+505)}$ arasında kalan yaklaşık 18 km'lik bölüm örnek olarak incelenmiştir. Belirtilen hat üzerinde TCDD tarafından belirli periyotlarla Matisa MPV-7 ve Roger 800 yol geometrisi ölçüm makinaları ile yapılan yol geometrisi ölçüm sonuçları bulunmaktadır. Bu iki yol geometrisi ölçüm makinasından elde edilen ölçüm sonuçları birleştirilerek yapılan poz çalışması ile birlikte poz öncesi ve poz sonrası olmak üzere yolun genel kalitesinin yıllar içerisindeki değişimi gözlemlenmiştir.

Konu ile ilgili literatürde yapılan çalışmalara bakıldığında demiryollarında genellikle yol bozulma modelleri, planlı bakım çalışmaları ve bu bakımların optimizasyonu ile ilgili çalışmaların olduğu görülmektedir. Uluslararası Demiryolu Birliği [2], tarafindan standart sapma yöntemi önerilmiştir. Hamid ve Gross [3], yol kalitesi indeksini temsil edecek çeşitli lineer modeller önermiştir. Sadeghi [4], W5, yol geometrisi indeksi (TGI), Q-index, yol kalitesi indeksi (TQI), yol pürüzlülük indeksi, J indeksi ve standart sapma gibi formülasyonlar ile yol geometrisi datasının istatistiksel dağılımını incelemiş̧ir. Berawi ve diğ. [5], yol geometrisi kalitesini standart sapma, yol kalitesi indeksi ve J sentetik katsayısı gibi farklı metodolojiler ile değerlendirmiştir. $\mathrm{Xu}$ ve diğ. [6], kısa dalga kusurların lineer regresyon ile modellemesini incelemiştir. Andrade ve Teixeira [7] , bakım ve buraj sonrasında ilk standart sapmaların lineer regresyon ile modellemesini incelemiştir. Quiroga ve Schnieder [8], nivelman parametresinin lognormal modellemesi ile çalışmıştır. Audley ve Andrews [9], buraj faaliyetlerinin etkisini lineer regresyon modeli ile incelemiştir. Khouy ve diğ. [10], İsveç Demiryollarında kullanılan K-değeri ile önleyici ve düzeltici bakımlar ile ilgili çalışmalar yapmıştır. Andrade ve Teixeira [11], plansız bakım çalışmalarının modellenmesini logistic regresyon modeli ile incelemiştir. Güler [12], çalışması ile düzeltici bakım çalışmalarına başvurmak yerine planlı bakım ve yenileme yönetim sistemlerinin optimizasyonunu genetik algoritmalar ile incelemiştir. Literatürde genellikle planlı bakım çalışmaları ile yapılan çalışmalar olması neticesinde düzeltici bakımlar ve etkileri örnek olay incelemesi olarak seçilen Kütahya - Afyonkarahisar illeri arasında belirlenen kesimde incelemeler yapılmıştır.

İnceleme alanı olarak bu hattın seçilme sebepleri; güzergahın 2013 yılı yaz aylarında tamamen yenilenerek poz geçirmesi ve güzergah üzerinde belirli aralıklarla yapılmış olan geçmiş yıllara ait MPV-7 ve Roger ölçüm sonuçlarının bulunmasıdır. Eskişehir - Konya Hattı içerisinde kalan Alayunt - Afyonkarahisar bölümünde 1982-1989 yılları arasında hat kısım kısım yenilenmiştir. Yoğun bir taşımacılık yapılmakta olan bu hat kesimi ekonomik ömrünü doldurduğundan dolayı 28.05.2013-05.07.2013 tarihleri arasında poz çalışmasına (yol yenilemesi) girmiştir. AlayuntÇöğürler istasyonları arası 05.07.2013 tarihine kadar yenilenmiştir. Yenilenen yolda yeni standartlara uygun UIC 60 ray ve HM Tipi B 70 beton travers kullanılmıştır ve balast yapısı tamamen yenilenmiştir. Bu hat üzerinde Alayunt - Çöğürler İstasyonları arasında 2013 yaz 
aylarında yapılan poz çalışmasından önce 13.04.2009, 20.09.2010, 11.04.2011, 16.04.2012 ve 15.04.2013 tarihlerinde gerçekleştirilmiş MPV-7 ölçüm sonuçları bulunmaktadır. Poz çalışmasından sonra ise 22.04.2014, 21.10.2014 ve 01.04.2019 tarihlerine ait MPV-7 ölçüm sonuçları ile 02.03.2015, 01.03.2016, 28.11.2017, 10.09.2018 ve 11.11.2019 tarihli Roger 800 ölçüm sonuçları bulunmaktadır. Söz konusu ölçüm sonuçları hattın poz çalışması öncesi ve sonrasındaki durumunu karşılaştırma açısından uygun olduğu düşünülmüş ve bu yönde çalışmalar yürütülmüştür. Ayrıca poz çalışmasına kadar bu hat kesiminde yol kalitesinin korunması amacıyla yapılan düzeltici bakım çalışmaları da mevcuttur. Bu düzeltici yol bakım çalışmalarının yol geometrisi kalitesine etkileri de ortaya koyulmaya çalışılmıştır.

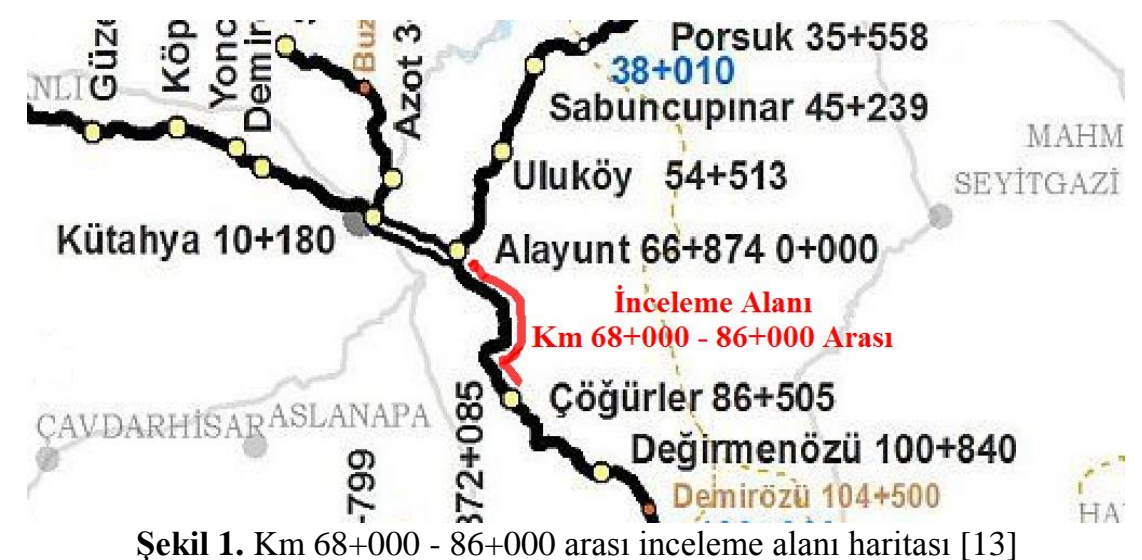

İncelenen yol bölümünün örnek olarak seçilen $\mathrm{Km} 68+000-86+000$ arasında, ilgili Kısım Şefliğinden elde edilen bilgiler 1şığında işletme hızlarına göre yol kesimi Km 68+000-77+963 aras1 $80 \mathrm{~km} / \mathrm{sa}<\mathrm{V}<120 \mathrm{~km} / \mathrm{sa}$ hız aralığında ve $\mathrm{Km} 77+963-86+000$ aras1 $0<\mathrm{V}<80 \mathrm{~km} / \mathrm{sa} \mathrm{h}$ hz aralığında olmak üzere iki ayrı hız grubuna bölünmüştür. İncelenen yol kesimine ait harita Şekil 1 'de yer almaktadır. Belirtilen yol kesimlerindeki yol geometrisi kalitesinin yıllar içerisindeki bozulma/iyileşme eğilimleri ile düzeltici bakımların etkileri EN 13848-5 standardında da yer alan standart sapma (standard deviation SD) kavramlarıyla tespit edilmeye çalışılmıştır. EN 13848-5 standardında yer alan standart sapma (SD) kavramı yol geometrisi kalitesinin belirlenmesinde kullanılan bir ölçüt olup yol geometrisi parametreleri için ayrı ayrı hesaplanmakta bunlarla ilgili yol geometrisindeki bozulmalar ve ihtiyaçlar belirlenebilmektedir. Söz konusu yol geometrisi parametreleri kısaca şunlardır; Fleş, demiryollarında bir daire yayını kesen kirişin herhangi bir noktasından daire yayına olan dik mesafe olarak tanımlanır [14]. Nivelman, demiryolunda düşey eksende ölçülen çeşitli noktaların teorik ve gerçek değerleri arasındaki yükseklik farklılıkları olarak tanımlanır. Ekartman, demiryollarında rayların iç kenarları arasındaki yuvarlanma yüzeyinden $14 \mathrm{~mm}$ aşağıda ölçülen açıklık olarak tanımlanır [15]. Burulma, bir boji düzleminde veya bojisiz araçlarda 3 tekerin raya basıp, bir tekerin yoldaki nivelman hatası nedeniyle raya basmaması neticesi tekerin boşta kalıp tekrar raya basması esnasında ray mantarı üstüne veya ray dışına basarak deraya sebebiyet verebilecek arızalar olarak tanımlanır [16]. Dever ise, yatay kurplarda diş ray dizisinin iç ray dizisine göre belirli bir miktarda yükseltilmesi olarak adlandırılır [14]. EN 13848-5 standardında yukarıda kısaca tanımlanan parametrelerden yalnızca fleş ve nivelman parametrelerine ilişkin SD limit değerleri bulunmaktadır.

EN 13848-5 standardında tanımlanan 3 temel yol geometrisi kalite düzeyi bulunmaktadır. Bu 3 kalite düzeyi yardımıyla yol geometrisi kusurlarının seviyeleri kategorize edilebilmektedir. Söz konusu 3 kalite düzeyi şunlardır;

- Uyarı eşiği (AL): Aşılması halinde; hat geometrisi koşullarının, bir sonraki planlı bakım çalışmaları kapsamında analiz edilmesini ve dikkate alınmasını ifade eden değerdir.

- Müdahale eşiği (IL): Aşılması halinde; bir sonraki ölçüme kadar güvenlik eşiğine varmadan düzeltici bakım gerektiren değeri ifade eder. 
- Acil müdahale eşiği (IAL): Aşılması halinde; kusurlar düzeltilinceye kadar, maksimum tren hızını düşürmek veya hattı işletmeye kapatmak şeklinde acil önlemler alınmasını gerektiren değerlerdir [17].

Yukarıda söz edilen Standart Sapma haricinde Kalite Endeksleri (QI) veya Genel Kalite Endeksi (OQI) gibi ölçütler ile yol geometrisinin kalite düzeyi belirlenmekte söz konusu 3 kalite düzeyine göre demiryolu altyapı sorumlusunu uyarmakta ve gerekli önlemleri almaya (hattın kontrol edilmesi ve izlenmesi, koruyucu bakım yapılması, düzeltici bakım yapılması veya yenileme çalışmalarının yapılması [1] gibi önlemlere) sevk etmektedir. Demiryolunda yapılan kontrol ve bakım çalışmalarında, hat geometrisi ölçümlerinin yanı sıra balastın durumu, bağlantı malzemelerinin durumu, traverslerin durumu, ray aşınması, ray kusurları ve ondülasyonların da detaylı olarak incelenmesi, yapılacak bozulma modellemelerinde bu parametrelerin de göz önüne alınması gerekmektedir. Ne var ki mekanik bozulma modellemeleri her farklı parametre için ayrı ayrı ele alınmalı ve bağımsız bozulma modellemeleri yapılması ideal olanıdır. Örneğin, balast bozulması için ayrı, ray aşınması için ayrı birer model oluşturulabilir ve bu modeller kapsamlı modelde birleştirilebilir[18].

\section{Metot}

Standart Sapma değerinin kullanılarak yol geometrisi kalitesinin belirlenmesinde seçilen bir yol kesiminde incelenen geometrik değişkene ait hatalar tespit edilmekte ve istatistiksel bir formülasyon olan Standart Sapma formülü ile hataların SD değerleri hesaplanmaktadır. EN 13848-5 standardında yer alan Tablo 1'de görülen SD-Hız grupları tablolarına göre uyarı eşiğinde (AL) değerlendirme yapılmaktadır. Yüksek standart sapma değeri yol kalitesinin kötü olduğuna, düşük standart sapma değeri ise tam tersine yüksek yol kalitesine işarettir [19].

$$
S=\sqrt{\frac{1}{n} \sum_{i=1}^{n}\left(x_{i}-\bar{x}\right)^{2}}
$$

$\bar{x}=$ Yol kusurunun ortalama değeri $(\mathrm{mm})$

$\mathrm{S}=$ Standart Sapma

$\mathrm{n}=$ Analiz edilen yol bölümünde kaydedilen sinyal sayısı

$\mathrm{xi}=$ Parametrenin o noktadaki değeri $(\mathrm{mm})$

Fransa merkezli Avrupa Demiryolu Araştırma Merkezi, doğrudan standart sapma (SD) yaklaşımının kullanılmasını önerir ve bazı Avrupa, Orta Doğu ve Asya ülkeleri tarafindan bu yöntem kullanılır [20]. EN 13848-5 standardında nivelman ve fleş parametrelerinin çeşitli hız gruplarına göre hata eşik değerleri SD değerleri Tablo 1 ve Tablo 2'de yer almaktadır. MPV-7, Roger $800 \mathrm{vb}$. yol geometrisi ölçüm makineleri ile hat üzerinde yapılan yol geometrisi ölçümleri Tablo 1 ve Tablo 2'de yer alan EN 13848-5 standardına göre değerlendirilmektedir.

Tablo 1. Nivelman parametresi eşik değerleri - standart sapma (SD) - hız grupları tablosu [17]

\begin{tabular}{cccccccc}
\hline Hizlar & \multicolumn{2}{c}{ AL $(\mathrm{mm})$} & \multicolumn{2}{c}{$\mathrm{IL}(\mathrm{mm})$} & \multicolumn{2}{c}{ IAL $(\mathrm{mm})$} & Standart Sapma $(\mathrm{mm})$ \\
$(\mathrm{Km} / \mathrm{s})$ & $\mathrm{D} 1$ & $\mathrm{D} 1$ & $\mathrm{D} 1$ & $\mathrm{D} 2$ & $\mathrm{D} 1$ & $\mathrm{D} 2$ & D1 \\
\hline $\mathrm{V} \leq 80$ & $12-18$ & N/A & $17-21$ & N/A & 28 & N/A & $2,3-3,0$ \\
$80<\mathrm{V} \leq 120$ & $10-16$ & N/A & $13-19$ & N/A & 26 & N/A & $1,8-2,7$ \\
$120<\mathrm{V} \leq 160$ & $8-15$ & N/A & $10-17$ & N/A & 23 & N/A & $1,4-2,4$ \\
$160<\mathrm{V} \leq 230$ & $7-12$ & $14-20$ & $9-14$ & $18-23$ & 20 & 33 & $1,2-1,9$ \\
$230<\mathrm{V} \leq 300$ & $6-10$ & $12-18$ & $8-12$ & $16-20$ & 17 & 28 & $1,0-1,5$ \\
\hline
\end{tabular}


Tablo 2. Fleş parametresi eşik değerleri - standart sapma (SD) - hız grupları tablosu [17]

\begin{tabular}{cccccccc}
\hline Hizlar & \multicolumn{2}{c}{ AL $(\mathrm{mm})$} & \multicolumn{2}{c}{$\mathrm{IL}(\mathrm{mm})$} & \multicolumn{2}{c}{$\mathrm{IAL}(\mathrm{mm})$} & Standart Sapma $(\mathrm{mm})$ \\
$(\mathrm{Km} / \mathrm{s})$ & $\mathrm{D} 1$ & $\mathrm{D} 1$ & $\mathrm{D} 1$ & $\mathrm{D} 2$ & $\mathrm{D} 1$ & $\mathrm{D} 2$ & D1 \\
\hline $\mathrm{V} \leq 80$ & $12-15$ & N/A & $15-17$ & N/A & 22 & N/A & $1,5-1,8$ \\
$80<\mathrm{V} \leq 120$ & $8-11$ & N/A & $11-13$ & N/A & 17 & N/A & $1,2-1,5$ \\
$120<\mathrm{V} \leq 160$ & $6-9$ & N/A & $8-10$ & N/A & 14 & N/A & $1,0-1,3$ \\
$160<\mathrm{V} \leq 230$ & $5-8$ & $10-15$ & $7-9$ & $14-17$ & 12 & 24 & $0,8-1,1$ \\
$230<\mathrm{V} \leq 300$ & $4-7$ & $8-13$ & $6-8$ & $12-14$ & 10 & 20 & $0,7-1,0$ \\
\hline
\end{tabular}

EN 13848-1 standardına göre ölçüm sistemlerinde dikkate alınması gereken dalga boyları aşağıda verilmiştir;

- İşletme hız1 $<160 \mathrm{~km} / \mathrm{h}$ olan hatlarda dikkate alınacak dalga boyu D1'dir.

- $160 \mathrm{~km} / \mathrm{h} \leq$ İşletme hızı $<300 \mathrm{~km} / \mathrm{h}$ olan hatlarda dikkate alınacak dalga boyu D1 ve D2'dir.

- İşletme hızı $\geq 300 \mathrm{~km} / \mathrm{h}$ olan hatlarda dikkate alınacak dalga boyu D1, D2 ve D3'tür. [21]

Tablo 3. Dalga boyu uzunlukları tablosu [21]

\begin{tabular}{cccc}
\hline Dalga Boyları & D1 & D2 & D3 \\
\hline $\begin{array}{c}\text { Nivelman için dalga } \\
\text { boyu uzunluğu }\end{array}$ & $3 \mathrm{~m}<\lambda<25 \mathrm{~m}$ & $25 \mathrm{~m}<\lambda<70 \mathrm{~m}$ & $70 \mathrm{~m}<\lambda<150 \mathrm{~m}$ \\
$\begin{array}{l}\text { Fleş için dalga } \\
\text { boyu uzunluğu }\end{array}$ & $3 \mathrm{~m}<\lambda<25 \mathrm{~m}$ & $25 \mathrm{~m}<\lambda<70 \mathrm{~m}$ & $70 \mathrm{~m}<\lambda<200 \mathrm{~m}$ \\
\hline
\end{tabular}

Sadeghi ve Askarinejad [22] tarafindan yapılan çalışmalarda ise söz konusu SD değeri kullanılarak yolun durumu direkt olarak kategorize edilerek, kötü, ortalama, iyi ve çok iyi şeklinde sınıflara ayrılmıştır. Bu çalışmada da elde edilen SD değerlerinin yorumlanmasında bu sınıflandırma referans değer olarak kabul edilmiştir. Referans değer olarak alınan yol durumu grupları aşağıda Tablo 4'te verilmektedir.

Tablo 4. Yol durumu grupları tablosu [22]

\begin{tabular}{cc}
\hline Yol Durumu & Standart Sapma Değeri $(\mathrm{mm})$ \\
\hline Kötü & $4<\mathrm{SD}$ \\
Ortalama & $2<\mathrm{SD}<4$ \\
İyi & $1<\mathrm{SD}<2$ \\
Çok iyi & $\mathrm{SD}<1$ \\
\hline
\end{tabular}

\section{Bulgular}

Daha önce de belirtildiği üzere çalışma yapılan Kütahya- Afyonkarahisar hattı üzerinde yer alan Alayunt - Çöğürler İstasyonları arasında 2013 yaz aylarında poz çalışması yapılmıştır. Söz konusu poz çalışması öncesi 13.04.2009, 20.09.2010, 11.04.2011, 16.04.2012 ve 15.04.2013 tarihlerinde gerçekleştirilmiş MPV-7 ölçüm sonuçları bulunmaktadır. Poz çalışmasından sonra ise 22.04.2014, 21.10.2014 ve 01.04.2019 tarihlerine ait MPV-7 ölçüm sonuçları ile 02.03.2015, 01.03.2016, 28.11.2017, 10.09.2018 ve 11.11.2019 tarihli Roger 800 ölçüm sonuçları bulunmaktadır. Ölçüm sonuçlarında sağ ve sol ray için ayrı ayrı fleş ile nivelman kusurları incelenmiş, hız gruplarına göre kusur sayıları tablo haline getirilmiştir. Tablo 5 ve Tablo 6 ' da yer alan 11 yıllık süreç içinde elde edilen sağ ve sol raya ait fleş ile nivelman kusur sayılarına ait toplam 2788 data ile incelemelerde bulunulmuştur.

Alayunt - Afyonkarahisar arasında inceleme yapılan Km 68+000 - 86+000 arasında işletme hızına göre hat iki hız sınıfına ayrılmış olup, yukarıda yer alan Tablo 7'de listelenen V1 (V $\leq 80)$ hız grubunun uzunluğu $9,963 \mathrm{~km}, \mathrm{~V} 2(80<\mathrm{V} \leq 120)$ hiz grubunun uzunluğu $8,037 \mathrm{~km}$ 'dir. 
Tablo 5. Km 68+000 - 77+963 arası (hız sınıfı $0<\mathrm{V}<80 \mathrm{Km} / \mathrm{s}$ ) hata sayılarının ölçüm yıllarına göre dağılımı

\begin{tabular}{|c|c|c|c|c|c|c|c|c|c|c|c|c|c|c|c|}
\hline \multirow{3}{*}{$\begin{array}{c}\text { Sira } \\
\text { No }\end{array}$} & \multirow{3}{*}{$\begin{array}{l}\text { Ölęüm } \\
\text { Dönemi }\end{array}$} & \multirow{3}{*}{$\begin{array}{c}\text { Ölçüm } \\
\text { Aleti }\end{array}$} & \multicolumn{13}{|c|}{$\begin{array}{l}\text { Alayunt-Afyon Arası Km: 68+00 ile 77+963 Arası Kusur Saylan (adet) } \\
\qquad(\mathrm{Hzz} \text { Sinıfı } 80<\mathrm{V}<120 \mathrm{Km} / \mathrm{s})\end{array}$} \\
\hline & & & \multicolumn{3}{|c|}{ Fleş D1 Sağ } & \multicolumn{3}{|c|}{ Fleș D1 Sol } & \multicolumn{3}{|c|}{ Nivelman D1 Sağ } & \multicolumn{3}{|c|}{ Nivelman D1 Sol } & \multirow{2}{*}{$\begin{array}{l}\text { Toplam } \\
\text { Kusur } \\
\text { (Adet) }\end{array}$} \\
\hline & & & $\mathbf{A L}$ & IL & IAL & AL & IL & IAL & AL & IL & IAL & $\mathbf{A L}$ & IL & IAL & \\
\hline 1 & Nisan 2009 & MPV-7 & 48 & 50 & 14 & 50 & 39 & 16 & 63 & 35 & 0 & 67 & 28 & 0 & 410 \\
\hline 2 & Eylül 2010 & MPV-7 & 36 & 45 & 13 & 41 & 35 & 8 & 45 & 22 & 0 & 38 & 12 & 1 & 296 \\
\hline 3 & Nisan 2011 & MPV-7 & 42 & 19 & 4 & 49 & 18 & 2 & 76 & 31 & 0 & 52 & 24 & 0 & 317 \\
\hline 4 & Nisan 2012 & MPV-7 & 51 & 19 & 1 & 53 & 19 & 5 & 71 & 13 & 0 & 73 & 22 & 0 & 327 \\
\hline 5 & Nisan 2013 & MPV-7 & 43 & 15 & 0 & 34 & 10 & 1 & 21 & 5 & 0 & 38 & 13 & 0 & 180 \\
\hline 6 & Nisan 2014 & MPV-7 & 1 & 1 & 0 & 1 & 2 & 0 & 10 & 4 & 0 & 11 & 3 & 0 & 33 \\
\hline 7 & Ekim 2014 & MPV-7 & 3 & 1 & 1 & 5 & 1 & 0 & 17 & 6 & 0 & 19 & 7 & 0 & 60 \\
\hline 8 & Mart 2015 & Roger & 0 & 0 & 0 & 0 & 0 & 0 & 0 & 0 & 1 & 0 & 0 & 1 & 2 \\
\hline 9 & Mart 2016 & Roger & 0 & 0 & 0 & 0 & 0 & 0 & 0 & 0 & 0 & 0 & 0 & 0 & 0 \\
\hline 10 & Kasım 2017 & Roger & 0 & 0 & 0 & 0 & 0 & 0 & 0 & 2 & 0 & 0 & 2 & 0 & 4 \\
\hline 11 & Eylül 2018 & Roger & 0 & 0 & 0 & 0 & 0 & 0 & 3 & 2 & 0 & 4 & 2 & 0 & 11 \\
\hline 12 & Nisan 2019 & MPV-7 & 2 & 0 & 0 & 1 & 0 & 0 & 3 & 1 & 0 & 0 & 4 & 0 & 11 \\
\hline 13 & Kasım 2019 & Roger & 0 & 0 & 0 & 0 & 0 & 0 & 0 & 1 & 0 & 0 & 1 & 0 & 2 \\
\hline \multirow{2}{*}{\multicolumn{3}{|c|}{ OPLAM KUSUR SAYISI }} & 226 & 150 & 33 & 234 & 124 & 32 & 309 & 122 & 1 & 302 & 118 & 2 & \multirow{2}{*}{1.653} \\
\hline & & & \multicolumn{3}{|c|}{409} & \multicolumn{3}{|c|}{390} & \multicolumn{3}{|c|}{432} & \multicolumn{3}{|c|}{422} & \\
\hline
\end{tabular}

Tablo 6. Km 77+963 - 86+000 arası (hız sınıfı $80<\mathrm{V}<120 \mathrm{Km} / \mathrm{s}$ ) hata sayılarının ölçüm yıllarına göre dağılımı

\begin{tabular}{|c|c|c|c|c|c|c|c|c|c|c|c|c|c|c|c|}
\hline \multirow{3}{*}{$\begin{array}{c}\text { Sira } \\
\text { No }\end{array}$} & \multirow{3}{*}{$\begin{array}{l}\text { Ölçüm } \\
\text { Dönemi }\end{array}$} & \multirow{3}{*}{$\begin{array}{l}\text { Ölçüm } \\
\text { Aleti }\end{array}$} & \multicolumn{13}{|c|}{$\begin{array}{l}\text { Alayunt-Afyon Arası Km: 77+963 ile 86+000 Arası Kusur Sayılan (adet) } \\
\text { (Hız Sinıfı } 0<\mathrm{V}<80 \mathrm{Km} / \mathrm{s} \text { ) }\end{array}$} \\
\hline & & & \multicolumn{3}{|c|}{ Fleş D1 Sağ } & \multicolumn{3}{|c|}{ Fleş D1 Sol } & \multicolumn{3}{|c|}{ Nivelman D1 Sağ } & \multicolumn{3}{|c|}{ Nivelman D1 Sol } & \multirow{2}{*}{$\begin{array}{l}\text { Toplam } \\
\text { Kusur } \\
\text { (Adet) }\end{array}$} \\
\hline & & & $\mathbf{A L}$ & IL & IAL & $\mathbf{A L}$ & IL & IAL & $\mathbf{A L}$ & IL & IAL & $\mathbf{A L}$ & IL & IAL & \\
\hline 1 & Nis an 2009 & MPV-7 & 11 & 18 & 12 & 35 & 27 & 12 & 64 & 12 & 0 & 57 & 8 & 0 & 256 \\
\hline 2 & Eylül 2010 & MPV-7 & 36 & 29 & 6 & 29 & 30 & 1 & 43 & 29 & 1 & 48 & 24 & 3 & 279 \\
\hline 3 & Nis an 2011 & MPV-7 & 38 & 17 & 1 & 42 & 14 & 0 & 37 & 14 & 0 & 46 & 8 & 0 & 217 \\
\hline 4 & Nis an 2012 & MPV-7 & 22 & 18 & 3 & 28 & 15 & 2 & 41 & 17 & 1 & 47 & 11 & 0 & 205 \\
\hline 5 & Nis an 2013 & MPV-7 & 19 & 12 & 0 & 38 & 5 & 0 & 26 & 4 & 0 & 43 & 9 & 0 & 156 \\
\hline 6 & Nis an 2014 & MPV-7 & 0 & 0 & 0 & 1 & 0 & 0 & 2 & 0 & 0 & 2 & 0 & 0 & \\
\hline 7 & Ekim 2014 & MPV-7 & 0 & 0 & 0 & 0 & 0 & 0 & 5 & 0 & 0 & 3 & 0 & 0 & 8 \\
\hline 8 & Mart 2015 & Roger & 0 & 0 & 0 & 0 & 0 & 0 & 0 & 0 & 0 & 0 & 0 & 0 & 0 \\
\hline 9 & Mart 2016 & Roger & 0 & 0 & 0 & 0 & 0 & 0 & 1 & 0 & 0 & 0 & 0 & 0 & 1 \\
\hline 10 & Kasım 2017 & Roger & 0 & 0 & 0 & 0 & 0 & 0 & 0 & 0 & 0 & 0 & 0 & 0 & 0 \\
\hline 11 & Eylül 2018 & Roger & 0 & 0 & 0 & 0 & 0 & 0 & 0 & 0 & 0 & 0 & 1 & 0 & 1 \\
\hline 12 & Nis an 2019 & MPV-7 & 0 & 0 & 0 & 0 & 0 & 0 & 1 & 1 & 0 & 1 & 0 & 0 & 3 \\
\hline 13 & Kasım 2019 & Roger & 0 & 0 & 0 & 0 & 0 & 0 & 1 & 0 & 0 & 2 & 1 & 0 & 8 \\
\hline \multirow{2}{*}{\multicolumn{3}{|c|}{ TOPLAM KUSUR SAYISI }} & 126 & 94 & 22 & 173 & 91 & 15 & 221 & 77 & 2 & 249 & 62 & 3 & \multirow{2}{*}{1.135} \\
\hline & & & \multicolumn{3}{|c|}{242} & \multicolumn{3}{|c|}{279} & \multicolumn{3}{|c|}{300} & \multicolumn{3}{|c|}{314} & \\
\hline
\end{tabular}

Tablo 7. Alayunt-Afyonkarahisar hattı km 68+000 - 86+000 arası maksimum müsaade edilebilir işletme hızlarına ait hat uzunlukları

\begin{tabular}{ccc}
\hline Hiz Grubu & $\begin{array}{c}\mathrm{H} 1 \mathrm{z} \\
(\mathrm{km} / \mathrm{sa})\end{array}$ & $\begin{array}{c}\text { Hat Uzunluğu } \\
(\mathrm{km})\end{array}$ \\
\hline V1 & $\mathrm{V} \leq 80$ & 9,963 \\
V2 & $80<\mathrm{V} \leq 120$ & 8,037 \\
\hline
\end{tabular}

\subsection{Fleş kusurları değerlendirmesi}

Fleş kusurlarının standart sapmasının bütün maksimum müsaade edilebilir hız grupları için ve üç yol kalitesi sınıfı (AL, IL ve IAL) için istatistiksel olarak önemli bir belirleyici olduğu ve yolun genel kalitesi hakkında direkt olarak demiryolu işletmecisine yol kalitesi hakkında bilgi verme fırsatı sunduğu Andrade ve Teixeira [11] tarafından yapılan çalışmalarda ortaya konulmuştur. Bu sebeple fleş kusurları detaylı olarak incelemeye alınmıştır. Çalışma alanı olarak belirlenmiş olan 
Alayunt - Çögürler İstasyonları arasında kalan Km 68+000 - 86+000 arasındaki bölümde mevcut tüm ölçüm sonuçlarından sağ fleş ve sol fleş hataları için ayrı ayrı olmak üzere 2 hız grubuna göre standart sapmaları hesaplanmıştır. Aşağıda fleş kusurlarının 3-25 m. (D1) dalga boyunda SD ve zaman değişkenleri ile oluşturulan grafikleri yer almaktadır.

Şekil 2 ve Şekil 3'te yer alan Km 68+000 - 77+963 arası sağ ve sol fleş kusurlarının standart sapma (SD) - zaman grafiğgi incelendiğinde SD değerinin ilk beş ölçümde EN 13848-5 standardında yer alan SD emniyet eşik değerinin üzerinde olduğu görülmektedir. Yolun ekonomik ömrünü tamamlamış olması nedeniyle yol kalitesinin geçici olarak iyileştirilmesi amacıyla bu dönem içerisinde düzeltici makineli bakım çalışmaları yürütülmüştür. Yıllar içerisinde kısım kısım yapılan bu bakım çalışmaları neticesinde hatta elde edilen iyileşmenin etkileri ilerleyen her ölçüm sonucundaki SD değerindeki azalmalardan görülebilmektedir.

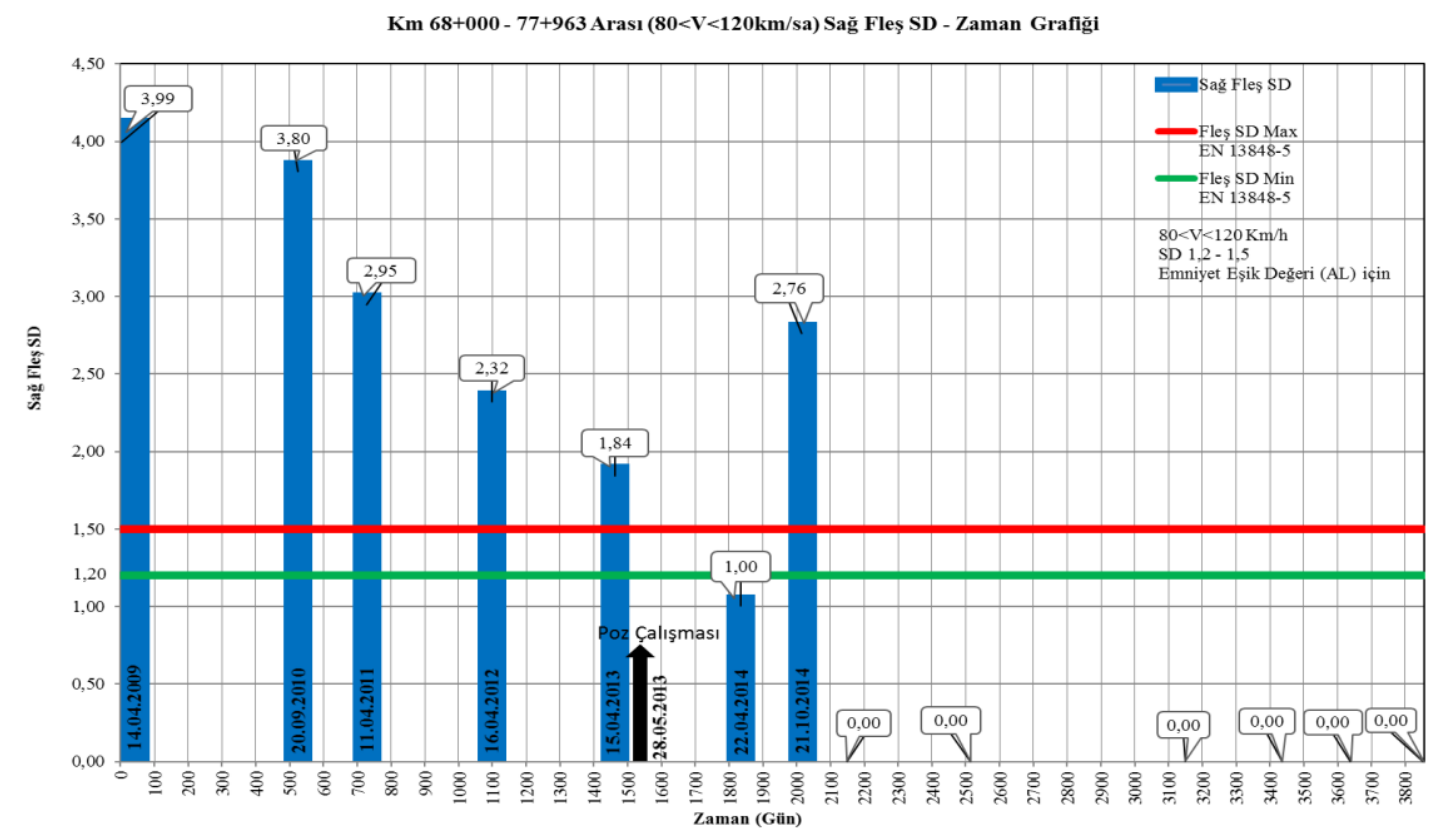

Şekil 2. Km $68+000-77+963$ arası $(80<\mathrm{V}<120 \mathrm{~km} / \mathrm{sa})$ sağ fleş SD - zaman grafiği

2013 yılı yaz aylarında yapılan ve Şekil 2 ve Şekil 3'te "Poz Çalışması" metni ile işaretlenen demiryolu yenileme çalışmasının sonrasında yapılan 2. ölçüm sonucuna (21.10.2014 tarihli ve grafikte 2016. güne denk gelen) göre SD değerinin emniyet eşik değerinin (AL) tekrar üzerine çıktığı görülmektedir. Ancak bu yükselme örneğin 1 hata sayısının 3 adet hata sayısına çıkması nedeniyle meydana gelmiş olup, demiryolunun poz çalışmasından önceki kötü haline döndüğünü değil de göreceli artı̧̧1 göstermektedir. Bu ölçüm sonucuna göre Tablo 4'te sunulan yol durumu değerlendirmeleri göz önüne alındığında yolun "ortalama" durumda olduğu söylenebilmektedir.

Yol yenileme çalışmasının yaklaşık 1 yıl sonrasında yolun kalitesinin "ortalama" seviyede görünmesinin sebebinin tamamen yenilenen yoldaki ilk oturmaların olduğu ya da zemin sslah çalışmalarının yeterli seviyede yapılmamış olabileceğidir. Nitekim sonraki yol ölçümlerinde bu standart sapma sıfıra yakın hale gelmiştir. Literatürde belirtildiği üzere; ilk aşamadaki oturmanın büyüklüğ̈̈ yolun yeniden yapım veya bakım çalışmaları sonrasında yapılan sıkıştırılmasına (buraj işlemlerine) büyük oranda bağlıdır [23]. Şekil 2 ve Şekil 3'te sunulan $\mathrm{Km} 68+000-77+963$ arasında $(80<\mathrm{V}<120 \mathrm{~km} / \mathrm{sa})$ hız grubunda standartların diğer hız grubuna göre $(0<\mathrm{V}<80 \mathrm{~km} / \mathrm{sa})$ daha katı olması nedeniyle $(1,2$ - 1,5 olan) SD değerinin Şekil 4 ve Şekil 5'te sunulan grafiklerdeki (1,5-1,8 olan) SD değerlerinden daha az olduğu gözlemlenmiştir. Daha açık bir ifadeyle, işletme hızı arttıkça, fleş ve nivelman toleransları da azalmaktadır. Tamamen yenilenen yolda Şekil 2 ve Şekil 3 'ten görüleceği üzere 2014 yılındaki (2016. gün) son ölçümden sonra 2019 
yılı sonuna kadar Tablo 6'dan görülebileceği üzere önemli derecede bir hata bulunmadığından standart sapma (SD) değeri de sıfır çıkmaktadır. Bu dönem içerisinde Tablo 4'te sunulan yol durumu değerlendirmelerine göre yolun durumunun "çok iyi”" olduğu söylenebilmektedir.

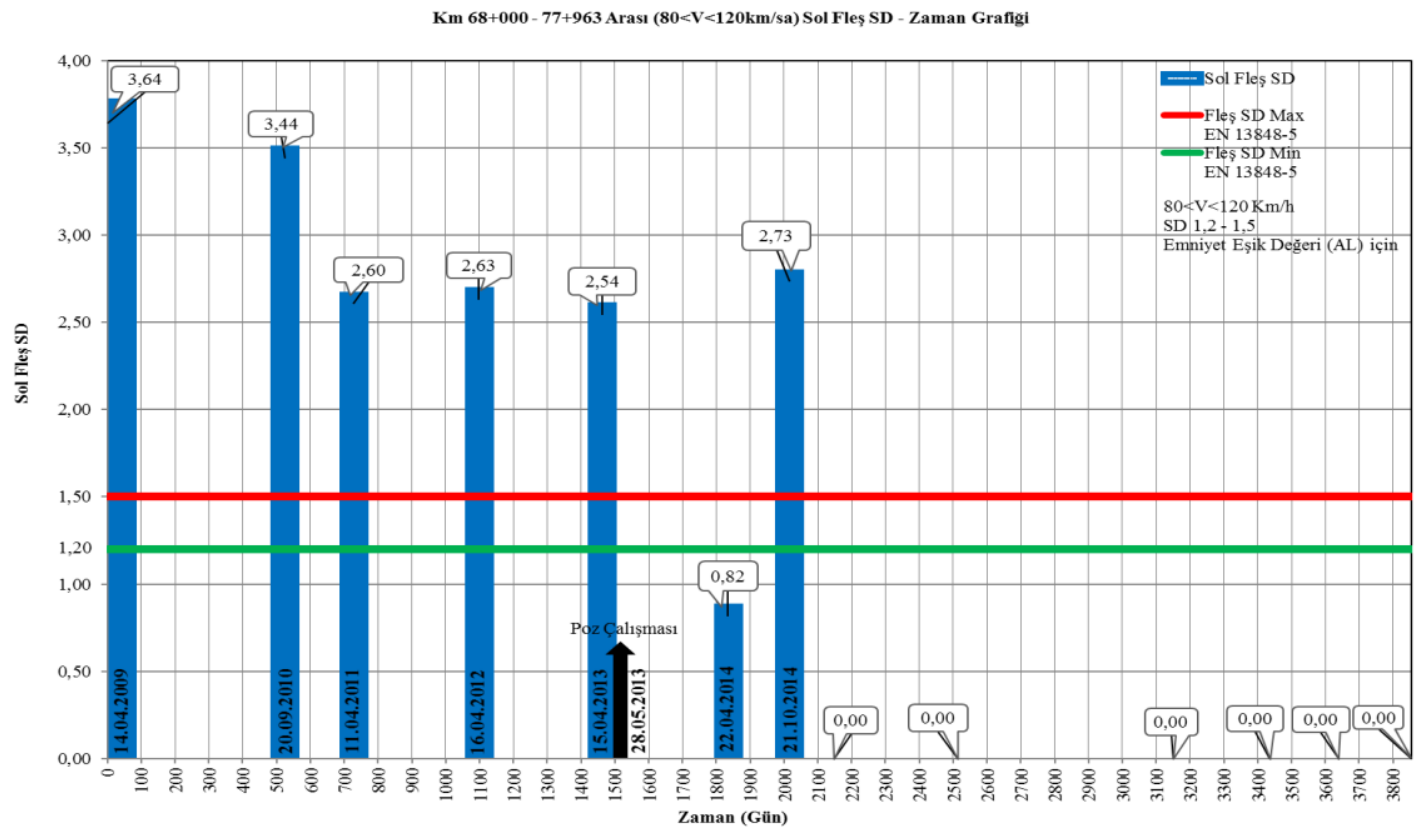

Şekil 3. $\mathrm{Km} 68+000-77+963$ arası $(80<\mathrm{V}<120 \mathrm{~km} / \mathrm{sa})$ sol fleş SD - zaman grafiği

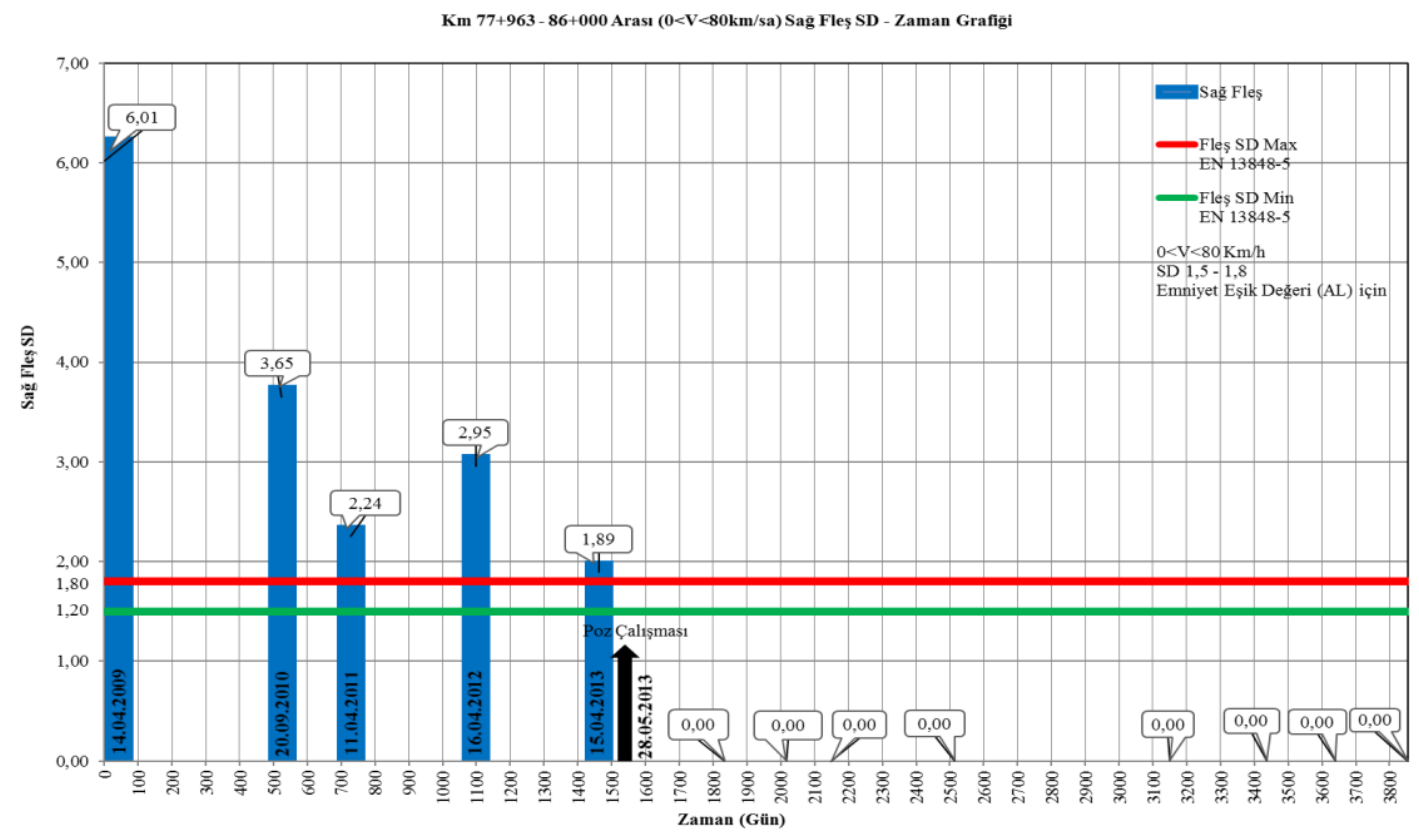

Şekil 4. $\mathrm{Km} 77+963-86+000$ arası $(0<\mathrm{V}<80 \mathrm{~km} / \mathrm{sa})$ sağ fleş $\mathrm{SD}$ - zaman grafiği

Şekil 4 ve Şekil 5'te yer alan Km 77+963 - 86+000 arası sağ ve sol fleş kusurlarının standart sapma (SD) - zaman grafiği incelendiğinde önceki bölümde olduğu gibi SD değerinin ilk beş ölçümde de EN 13848-5 standardında yer alan SD emniyet eşik değerinin üzerinde olduğu görülmektedir. Yolun ekonomik ömrünü tamamlamıș olması nedeniyle yol kalitesinin geçici olarak iyileştirilmesi amaciyla bu dönem içerisinde (ilk 1500 günlük zaman diliminde) düzeltici makineli bakım çalışmaları yürütülmüştür. Bu bakım çalışmaları neticesinde SD değerindeki 
azalmalar ve dalgalanmalar görülmektedir. Düzeltici bakım çalışmaları sayesinde yolun kalitesinde diğer hız grubuna göre $(80<\mathrm{V}<120 \mathrm{~km} / \mathrm{sa})$ daha etkili bir artış sağlandığı söylenebilir.

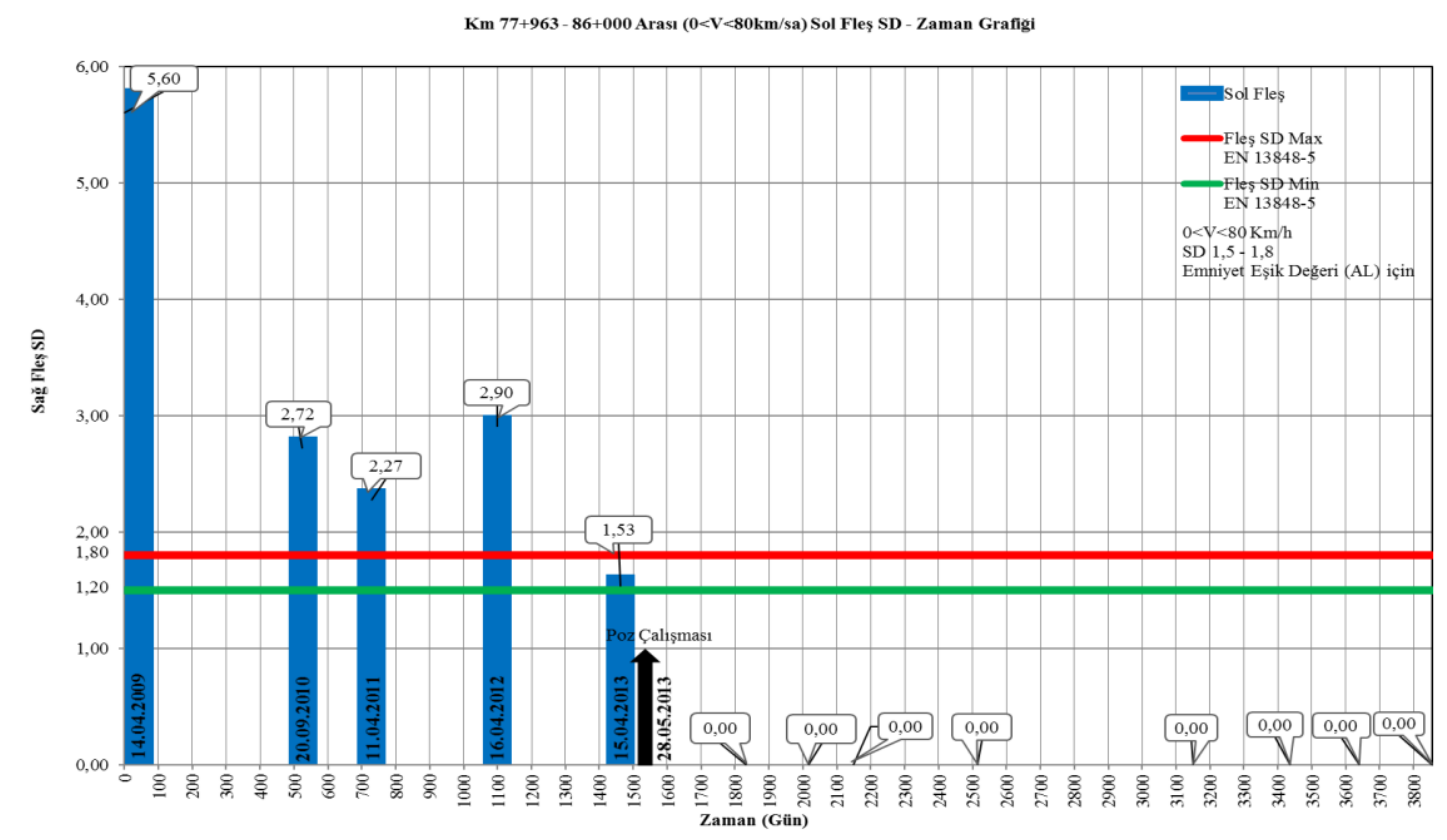

Şekil 5. Km 77+963 - 86+000 arası $(0<\mathrm{V}<80 \mathrm{~km} / \mathrm{sa})$ sol fleş SD - zaman grafiğgi

2013 yılı yaz aylarında (28.05.2013-05.07.2013 tarihleri arasında grafiklerde 1505. ve 1543. günlere tekabül eden) yapılan yol yenileme çalışmasının sonrasında yapılan ölçüm sonuçlarında SD değerinin emniyet eşik değerinin (AL) altında kaldığı görülmektedir. Bu ölçüm sonucuna göre Tablo 4'te sunulan yol durumu değerlendirmeleri göz önüne alındığına yolun "çok iyi” durumda olduğu söylenebilmektedir. Km $68+000-77+963$ arasında $(80<\mathrm{V}<120 \mathrm{~km} / \mathrm{sa}) \mathrm{h} 1 \mathrm{z}$ grubunda standartların diğer hız grubuna göre $(0<\mathrm{V}<80 \mathrm{~km} / \mathrm{sa})$ daha katı olması nedeniyle SD değeri daha fazla çıkmıştır, daha açık bir ifadeyle geometrik tolerans daha fazladır. Tamamen yenilenen yolda Şekil 4 ve Şekil 5’ten görüleceği üzere 2014 yılındaki (2016. gün) son ölçümden sonra 2019 yılı sonuna kadar önemli derecede bir hata bulunmamaktadır. Bu dönem içerisinde Tablo 4'te sunulan yol durumu değerlendirmelerine göre yolun durumunun "çok iyi” olduğu söylenebilmektedir.

Yolun başlangıçtaki kalitesinin yüksek olması, yolun kalitesini daha fazla korumakta ve bozulmalar için eşik değerine gelmesinin daha uzun zaman aldığı görülmektedir [24]. Şekil 4 ve Şekil 5'te görüleceği üzere kapsamlı yol yenileme sonrasında yolun ilk kalitesinin artmış olması sebebiyle SD değerlerinde herhangi bir artış görülmemekte, yolun kalitesinin uzun süre korunduğu çıkarımı yapılabilmektedir. Sadeghi ve Askarinejad [25] tarafindan yapılan çalışmalarda da trafik, bakım çalışmaları, hattan geçen toplam yük miktarı ve işletme hızının yanı sıra yolun ilk kalitesinin yüksek olmasının yolun bozulma oranında en büyük etkilerden birine sahip olduğu ortaya konulmuştur. Muinde [20] tarafından yapılan çalışmada iki ardışık ölçüme ait standart sapmalar arasındaki oran "buraj seviyesi parametresi" olarak önerilmiştir.

$$
\mathrm{BSP}=\frac{\mathrm{SD}_{\mathrm{i}}}{\mathrm{SD}_{\mathrm{i}-1}}
$$

BSP $=$ Buraj seviyesi parametresi (yüzde)

$\mathrm{SD}=$ Standart Sapma

Eşitlik 2'de yer alan buraj seviyesi parametresine benzer şekilde yapılan düzeltici bakımların etkilerini görmek amacıyla ilk ölçüm sonucu ve yol yenilemesi öncesindeki son ölçüm sonucu 
referans alınarak değerlendirme yapılmıştır. Şekil 2 ve Şekil 3'te yer alan Km 68+000 - 77+963 aras1 $(80<\mathrm{V}<120 \mathrm{~km} / \mathrm{sa})$ sağ ve sol fleş kusurlarının standart sapma (SD) - zaman grafiğinde yer alan SD değerlerine göre yol yenilemesi öncesinde yapılan düzeltici bakımların etkisinin sağ fleş için yaklaşık \%54, sol fleş için yaklaşık \%30 seviyelerinde iyileşme sağlandığı belirlenmiştir. Şekil 4 ve Şekil 5 'te yer alan Km $77+963-86+000$ arası $(0<\mathrm{V}<80 \mathrm{~km} / \mathrm{sa})$ sağ ve sol fleş kusurlarının standart sapma (SD) - zaman grafiğinde yer alan SD değerlerine göre yol yenilemesi öncesinde yapılan düzeltici bakımların etkisinin ise sağ fleş için yaklaşık \%69, sol fleş için yaklaşık \%73 seviyelerinde iyileşme sağlandığı görülmüştür. Buradan da anlaşılacağı üzere yol geometrisi standartlarının daha esnek olduğu düşük hız gruplarında yapılan düzeltici bakım çalışmalarının hata sayısını azaltmada yüksek hız gruplarına göre daha etkili olduğu söylenebilmektedir. Yol yenileme çalışması (poz) öncesi 2009-2014 yılları arasındaki ölçümlerin sağ ve sol fleş parametresinin SD değeri lineer ve üstel yaklaşım modelleri ile de ayrı ayrı incelenmiştir. Sonuçları aşağıda Şekil 6, Şekil 7, Şekil 8 ve Şekil 9'da yer almaktadır. Demiryolunda yapılan düzeltici bakımların etkisini görmek amacıyla her iki yaklaşım ile yaklaşık modeller elde edilmiştir.
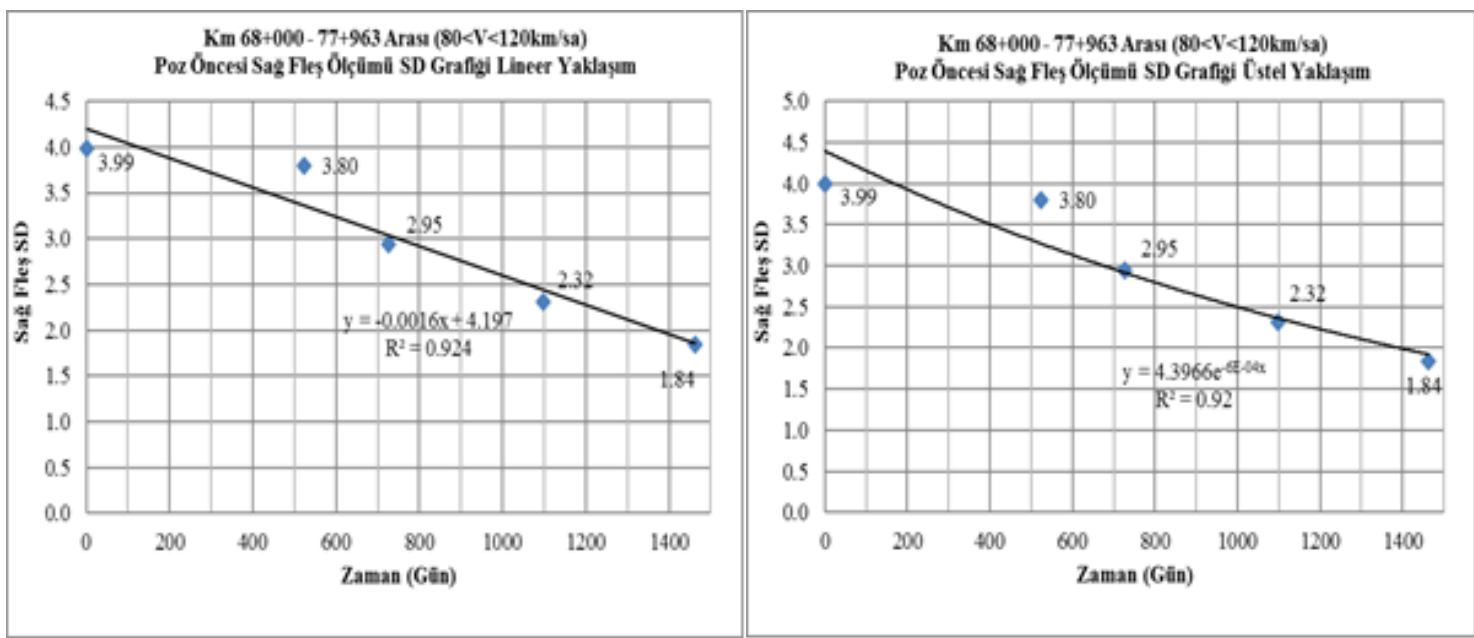

Şekil 6. $\mathrm{Km} 68+000-77+963$ arası $(80<\mathrm{V}<120 \mathrm{~km} / \mathrm{sa})$ sağ fleş SD - zaman grafiği a) lineer yaklaşım b) üstel yaklaşım
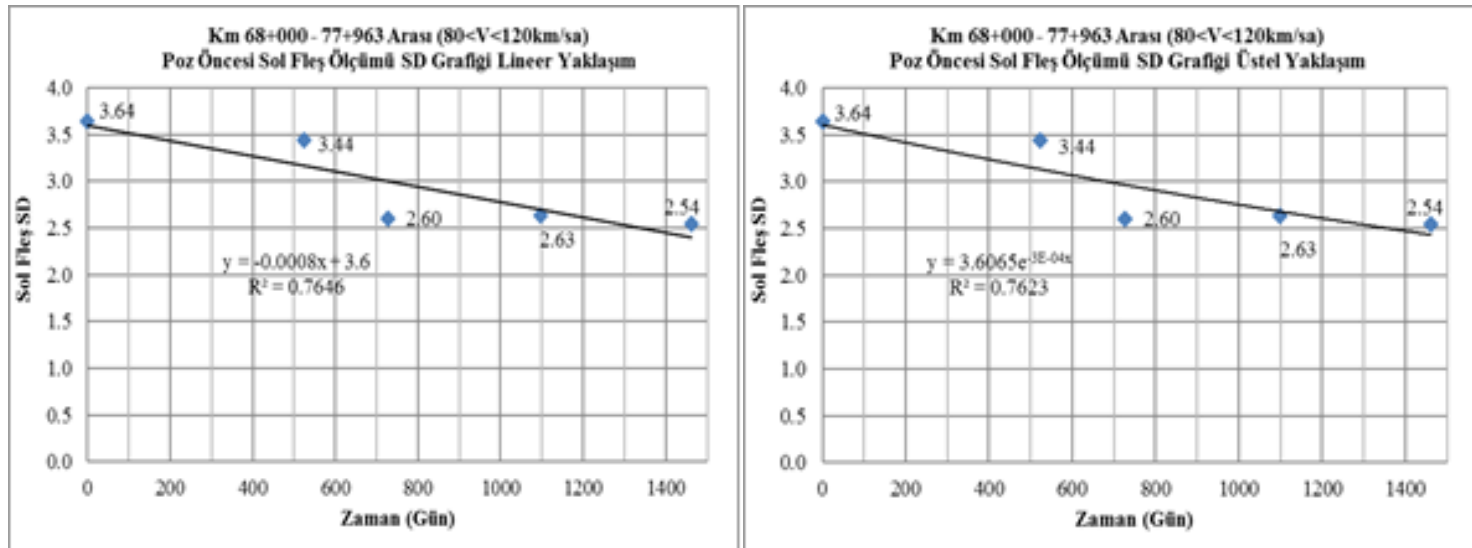

Şekil 7. Km 68+000 - 77+963 arası $(80<\mathrm{V}<120 \mathrm{~km} / \mathrm{sa})$ sol fleş SD - zaman grafiği a) lineer yaklaşım b) üstel yaklaşım

$\mathrm{Bu}$ yöntemi kullanmanın avantaj1, 0 ile 1 arasında bir büyüklük aralığına sahip regresyon değerinin karesinden $\left(\mathrm{R}^{2}\right)$ tahminimizin doğruluğunu gösterebilmesidir [26]. Daha yüksek $\mathrm{R}^{2}$, veri noktaları arasında daha güçlü korelasyon ve bozulma/iyileşme oranının daha doğru tahmini anlamına gelmektedir [5]. Aşağıda Tablo 8'de bulunan sağ ve sol fleş $\mathrm{R}^{2}$ değerleri 
karşılaştırıldığında, bu modellemelerde $\mathrm{R}^{2}$ değerinin 1'e daha yakın olması sebebiyle, Km 68+000 $-77+963$ arasında $(80<\mathrm{V}<120 \mathrm{~km} / \mathrm{sa})$ yolun kalitesindeki iyileşmelerin lineer ilerlediği, $\mathrm{Km}$ $77+963-86+000$ arasında $(0<\mathrm{V}<80 \mathrm{~km} / \mathrm{sa})$ yolun kalitesindeki iyileşmelerin üstel ilerlediği gözlemlenmiştir.
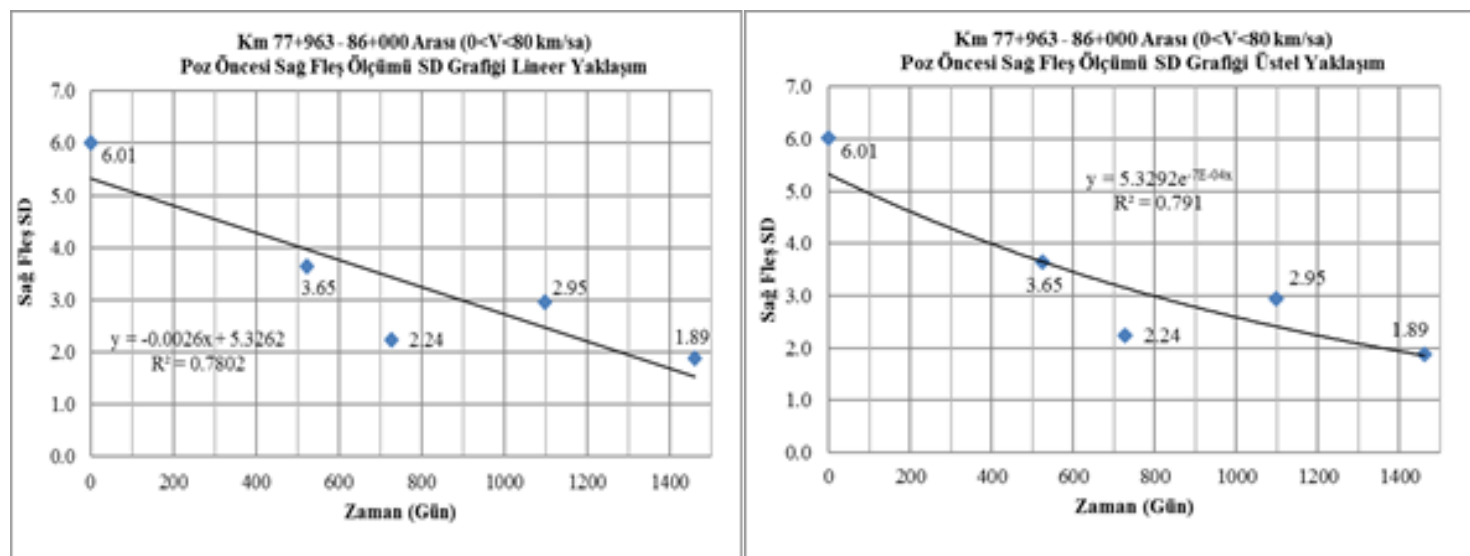

Şekil 8. $\mathrm{Km} 77+963-86+000$ arası $(0<\mathrm{V}<80 \mathrm{~km} / \mathrm{sa})$ sağ fleş $\mathrm{SD}$ - zaman grafiği a) lineer yaklaşım b) üstel yaklaşım
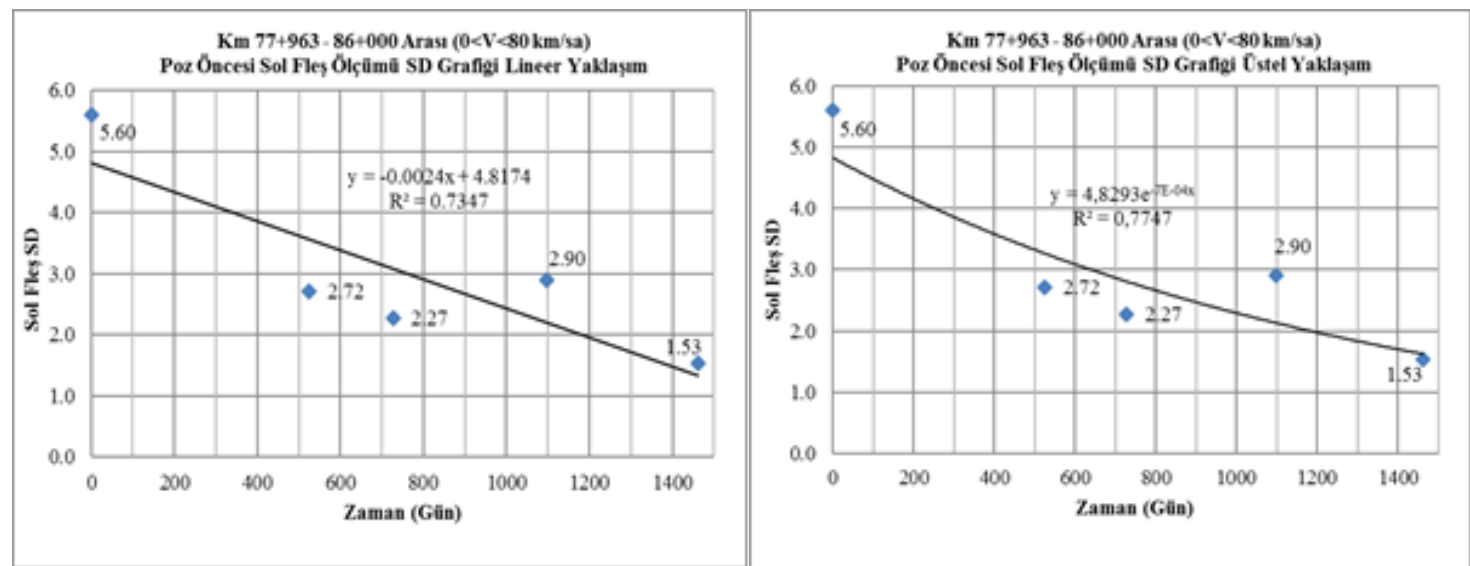

Şekil 9. $\mathrm{Km} 77+963-86+000$ arası $(0<\mathrm{V}<80 \mathrm{~km} / \mathrm{sa})$ sol fleş SD - zaman grafiği a) lineer yaklaşım b) üstel yaklaşım

Tablo 8. Poz öncesi sağ ve sol fleş hatalarının lineer ve üstel yaklaşıma göre $\mathrm{R}^{2}$ değerleri

\begin{tabular}{ccccc}
\hline \multirow{2}{*}{$\begin{array}{c}\text { Yaklaşım } \\
\text { Modeli }\end{array}$} & \multicolumn{2}{c}{ Km $68+000-77+963$} & \multicolumn{2}{c}{ Km $77+963-86+000$} \\
& arası $(80<\mathrm{V}<120 \mathrm{~km} / \mathrm{sa})$ & \multicolumn{2}{c}{ arası $(0<\mathrm{V}<80 \mathrm{~km} / \mathrm{sa})$} \\
Sol Fleş $\mathrm{R}^{2}$ & Sağ Fleş $\mathrm{R}^{2}$ & Sol Fleş $\mathrm{R}^{2}$ & Sağ Fleş $\mathrm{R}^{2}$ \\
\hline Lineer Yaklaşım & 0,7646 & 0,9240 & 0,7347 & 0,7802 \\
Üstel Yaklaşım & 0,7623 & 0,9200 & 0,7747 & 0,7910 \\
\hline
\end{tabular}

Yolun ilk kalitesinin düşük olduğu poz öncesinde yapılan düzeltici bakımlar hız sınırının düşük olduğu Km 77+963 - 86+000 arasında standartların daha esnek olması sebebiyle yapılan bir bakım çalışması ile hata sayılarında daha fazla azalma elde edilebileceği dolayısıyla düzetici bakımların düşük hız gruplarında daha etkili olduğu ve bu bölümde iyileşme değişimlerinin üstel yaklaşım modeline daha yakın olduğu söylenebilir. Bunun yanında hızın daha yüksek olduğu Km $68+000$ - 77+963 arasında standartların daha rijit olması sebebiyle hata eşik seviyelerindeki (AL, IL, IAL) iyileşmelerin toplam hata sayısını azaltmadaki etkisinin az olduğu, sonuç olarak düzeltici bakımların etkisinin daha sınırlı seviyede kaldığı kaldığı ve daha kapsamlı "önleyici" ve "öngörücü" (pretentive and predictive maintenance) çalışmalarının yapılması gerektiği çıkarımı yapılabilmektedir. 


\subsection{Nivelman kusurları değerlendirmesi}

Önceki bölümde değerlendirmesi yapılan fleş kusurlarına ilave olarak çalışma alanı olarak belirlenmiş olan Alayunt - Çögürler İstasyonları arasında kalan Km 68+000 - 86+000 arasındaki bölümde mevcut tüm ölçüm sonuçlarından sağ nivelman ve sol nivelman hataları için ayrı ayrı olmak üzere 2 hız grubuna göre standart sapmaları hesaplanmıştır. İncelenen SD değerinin aynı yol kesiminde yer alan fleş ölçümlerine benzer şekilde ilerlemediği görülmektedir. Yolun ekonomik ömrünü tamamlamış olması nedeniyle yol kalitesinin geçici olarak iyileştirilmesi amacıyla bu dönem içerisinde düzeltici makineli bakım çalışmaları yürütülmüştür. Bu bakım çalışmaları neticesinde diğer hız grubunda olduğu üzere SD değerinde dalgalanmalar görülmektedir. Nivelman parametresi için de fleş hatalarına benzer şekilde lineer ve üstel yaklaşım ile incelemeler yapılmıştır. Fleş kusurları değerlendirmesi bölümünde de izah edildiği üzere Tablo 9'da görülen $\mathrm{R}^{2}$ değerinin 1'e yakın olmaması sebebiyle elde edilen nivelman kusurları standart deviasyon değerlerinin bozulma/iyileşme oranının tahmininde uygun olmayacağı düşünülmektedir.

Tablo 9. Poz öncesi sağ ve sol nivelman hatalarının lineer ve üstel yaklaşıma göre $\mathrm{R}^{2}$ değerleri

\begin{tabular}{ccccc}
\hline & \multicolumn{2}{c}{$\mathrm{Km} 68+000-77+963$} & \multicolumn{2}{c}{$\mathrm{Km} 77+963-86+000$} \\
Yaklaşım & \multicolumn{2}{c}{ arası $(80<\mathrm{V}<120 \mathrm{~km} / \mathrm{sa})$} & \multicolumn{2}{c}{ arası $(0<\mathrm{V}<80 \mathrm{~km} / \mathrm{sa})$} \\
Modeli & Sol Nivelman & Sağ Nivelman & Sol Nivelman & Sağ Nivelman \\
& $\mathrm{R}^{2}$ & $\mathrm{R}^{2}$ & $\mathrm{R}^{2}$ & $\mathrm{R}^{2}$ \\
\hline Lineer Yaklaşım & 0,0390 & 0,4316 & 0,0609 & 0,0003 \\
Üstel Yaklaşım & 0,0467 & 0,4633 & 0,0621 & 0,0007 \\
\hline
\end{tabular}

Yapılan düzeltici bakım çalışmalarının herhangi bir hız grubu için nivelman hata sayılarını azaltmada daha etkili olabileceği sonucuna varılamamıştır. Bunun sonucunda, yolun genel kalitesinin belirlenmesinde nivelman kusurlarının standart sapma değerinin fleş kusurlarında olduğu gibi üç yol kalitesi sınıfı (AL, IL ve IAL) için istatistiksel olarak tek başına yeterli bir ölçüt olamayacağ1 sonucuna varılabilmektedir. Önceki bölümde gösterildiği üzere fleş kusurlarında Vale ve Lurdes [27] tarafından yapılan çalışmaya benzer sonuçlar elde edilmesine rağmen, nivelman kusurlarına ait sonuçlarda bozulma/iyileşme oranı-yol durumunu ilişkilendirmek üzere anlamlı sonuçlar elde edilememiştir.

\section{Sonuç}

Yaklaşı 11 yıllık süreç (2009-2019) içinde temin edilen yol geometrisi ölçüm sonuçları ile EN 13848-5 standardına göre farklı hız gruplarında yol geometrisi kusurları ile ilgili incelemeler yapılmıştır. Ekartman, nivelman, dever ve burulma kusurlarının yanında bu çalışmada fleş ve nivelman kusurları detaylı olarak ele alınmıştır. Yapılan çalışmada, zemin etkisi, farklı oturmalar gibi çeşitli etmenler nedeniyle nivelman parametresine ait ölçüm sonuçlarında gerçekleştirilen düzeltici bakım çalışmalarının faydalı etkisi görülmekle birlikte, etkilerini direkt olarak ortaya çıkartabilecek şekilde anlamlı sonuçlar elde edilememiştir. Buna karşılık, literatürde yapılan çalışmalarda da olduğu üzere; fleş kusurlarının standart sapmasının bütün maksimum müsaade edilebilir hız grupları için ve üç yol kalitesi sınıfı (AL, IL ve IAL) için istatistiksel olarak önemli bir belirleyici olduğu ve yolun genel kalitesi hakkında direkt olarak demiryolu işletmecisine yol kalitesi hakkında bilgi verme firsatı sunduğu görülmektedir. Yaklaşık 11 yıllık ölçümlerden elde edilen veriler ışığında, fleş kusurlarının ve bu kusurların standart sapmasının yol geometrisinin durumunu tespiti için önemli birer parametre olduğu sonucuna varılmaktadır.

Yolun tamamıyla yenilenmesi ile yolun başlangıç kalitesi artmış, poz sonrasında yolun kalitesi çok daha uzun süre korunmuştur. Yolun ilk kalitesinin düşük olduğu dönemlerde, yolun bozulma eğiliminin daha fazla olduğu görülmektedir. Belirtilen yol kesimleri içerisinde yapılan örnek olay 
incelemesinde, demiryolunda yapılan düzeltici bakımların, yol geometrisi standartlarının daha esnek olduğu düşük hız gruplarında $(0<\mathrm{V}<80 \mathrm{~km} / \mathrm{sa})$ hata sayısını azaltmada ortalama \%71 oranında etkili olduğu görülürken, yüksek hız gruplarında $(80<\mathrm{V}<120 \mathrm{~km} / \mathrm{sa})$ hata sayısını azaltmada düzeltici bakımların etkisinin ortalama $\% 42$ oranında kaldığı belirlenmiştir. Yapılan çalışmada sonuç olarak, düşük hız gruplarında $(0<\mathrm{V}<80 \mathrm{~km} / \mathrm{sa})$ düzeltici bakımların yolun kalitesinin artırılmasında daha yüksek hız gruplarına $(80<\mathrm{V}<120 \mathrm{~km} / \mathrm{sa})$ göre daha etkili olduğu, yüksek hız gruplarında ve daha kapsamlı "önleyici" ve "öngörücü" (pretentive and predictive maintenance) çalışmalarının yapılması gerektiği görülmüştür.

Uygulama yapılan hattın konvensiyonel hatta belirli bir yol kesimi olması sebebiyle, çalışma yüksek hızlı tren hatlarında daha yüksek hız gruplarında güncellenerek önleyici, öngörücü ve düzeltici bakım faaliyetlerinin farklı etkileri ortaya konulabilir. Yüksek hızlı tren hatlarında bakım ve onarım sürelerinin çok kısıtlı olması nedeniyle bakım faaliyetlerinin daha verimli olması için yapılan çalışma geliştirilebilir.

\section{Teşekkür}

$\mathrm{Bu}$ çalışmanın temelini oluşturan yol geometrisi ölçüm sonuçlarını temin etmiş olduğumuz TCDD 71. Yol Bakım Onarım Müdürlüğü Müdür ve personeline katkılarından dolayı teşekkürü borç biliriz.

\section{Kaynakça}

[1] TCDD hat bakımı el kitabı, TCDD Yol Dairesi Başkanlığı, Ankara, 2013.

[2] Quantitative evaluation of geometric track parameters determining vehicle behaviour, International Union of Railways Office of Research and Experiments (ORE), C152, RP1,1981.

[3] A. Hamid, A. Gross, "Track-quality indices and track-degradation models for maintenance-of-way planning," Transportation Research Record, vol. 802, pp. 2-8, 1981.

[4] J. Sadeghi, "Development of railway track geometry indexes based on statistical distribution of geometry data," Journal of Transportation Engineering, vol. 136, no. 8, pp. 693-700, 2010.

[5] A.R.B. Berawi, R. Delgado, R. Calçada, C. Vale, "Evaluating track geometrical quality through different methodologies," International Journal of Technology, vol. 1, no. 1, pp. 38-47, 2010.

[6] P. Xu, Q. Sun, R. Liu, F. Wang, "A short-range prediction model for track quality index," Proceedings of the Institution of Mechanical Engineers Part FJournal of Rail and Rapid Transit, vol. 225, pp. 277 285, 2011.

[7] A. Andrade, P. Teixeira, "Uncertainty in rail-track geometry degradation: Lisbon-Oporto line case study," Journal of Transportation Engineering, vol. 687, pp. 193-200, 2011.

[8] L. Quiroga, E. Schnieder, "Modelling high speed railroad geometry ageing as a discrete-continuous process," Proceedings of the stochastic modeling techniques and data analysis international conference, SMTDA, Chania Crete Greece, 8-11 June 2010, pp.655-666.

[9] M. Audley, J. Andrews, "The effects of tamping on railway track geometry degradation," Proceedings of the Institution of Mechanical Engineers Part FJournal of Rail and Rapid Transit, vol. 227, no. 4, pp. 376-39, 2013.

[10]I.A. Khouy, P. Larsson-Kråik, A. Nissen, U. Juntti, H. Schunnesson, "Optimisation of track geometry inspection interval," Proceedings of the Institution of Mechanical Engineers Part FJournal of Rail and Rapid Transit, vol. 228, no. 5, pp. 546-556, 2014.

[11] A.R. Andrade, P.F. Teixeira, "Unplanned-maintenance needs related to rail track geometry," Proceedings of the Institution of Civil Engineers-Transport, vol. 167, no. 6, pp. 400-410, 2014.

[12]H. Güler, "Optimisation of railway track maintenance and renewal works by genetic algorithms," Građevinar, vol. 68, no. 12., 2017.

[13]Rayhaber, "TCDD demiryollari haritası 2019 yüksek çözünürlük," 2019. [Online]. Available: https://rayhaber.com/2019/07/tcdd-demiryollari-haritasi-2019-yuksek-cozunurluk/ [Accessed November 30, 2020]

[14] İ. Kaçer, Kısım şefi el kitabi, TCDD Ankara Eğitim Merkezi Müdürlüğü, Ankara, 2005.

[15] V.A. Profillidis, Railway engineering, Ashgate-Publishing Group, Aldershot, Brookfield USA, 2000.

[16]İ. Kaçer, İ. Bağbaşı, Üst yapi tekniği ve yolun bakimi, Ankara, 2010. 
[17] Railway Applications-Track-Track Geometry Quality, Part 5: Geometric quality levels - Plain line, switches and crossings, EN 13848-5:2017, European Committee for Standardization, 2017.

[18] A.R. Andrade, "Renewal decisions from a life-cycle cost (LCC) perspective in railway infrastructure: an integrative approach using separate LCC models for rail and ballast components," M.Sc. Thesis, Department of Civil Engineering, Technical University of Lisbon, Portugal, 2008.

[19] A.B. Berawi, "Improving railway track maintenance using power spectral density (PSD)," Ph.D. dissertation, Faculdade De Engenharia Universidade Do Porto, Portugal, 2013.

[20] M.S. Muinde, "Railway track geometry inspection optimization," M.Sc. Thesis, Department of Civil, Environmental and Natural Resources Engineering, Luleå University of Technology, Sweden, 2018.

[21] Railway Applications-Track-Track Geometry Quality, Part 1: Characterization of track geometry, EN 13848-1:2019, European Committee for Standardization, 2019.

[22] J. Sadeghi, H. Askarinejad, "Application of neural networks in evaluation of railway track quality condition," Journal of Mechanical Science and Technology, vol. 26, no. 1, pp. 113-122, 2012.

[23] M.V. Taciroğlu, "Demiryolu hat oturmasinin matematiksel modelleri ve hat oturmasina etki eden parametrelerin incelenmesi," Mühendislik Bilimleri ve Tasarım Dergisi, vol. 4, no .3, pp. 239-246, 2016.

[24] Y. Sato, "Optimum track structure considering track deterioration in ballasted track," in Proceedings Sixth International Heavy Haul Railway Conference, Cape Town, South Africa, 1997.

[25] J. Sadeghi, H. Askarinejad, "Development of improved railway track degradation models," Structure and Infrastructure Engineering: Maintenance, Management, Life-Cycle Design and Performance, vol. 6, no. 6, pp. 675-688, 2010.

[26] J. Sadeghi, H. Askarinejad, "Investigation on effect of track structural conditions on railway track geometry deviations," Proceeding of the Institution of Mechanical Engineers, Part F, Journal of Rail and Rapid Transit, vol. 223, no. 4, pp. 415-425, 2009.

[27]C. Vale, S.M. Lurdes, "Stochastic model for the geometrical rail track degradation process in the Portuguese railway northern line," Reliability Engineering and System Safety, vol. 116, pp. 91-98, 2013.
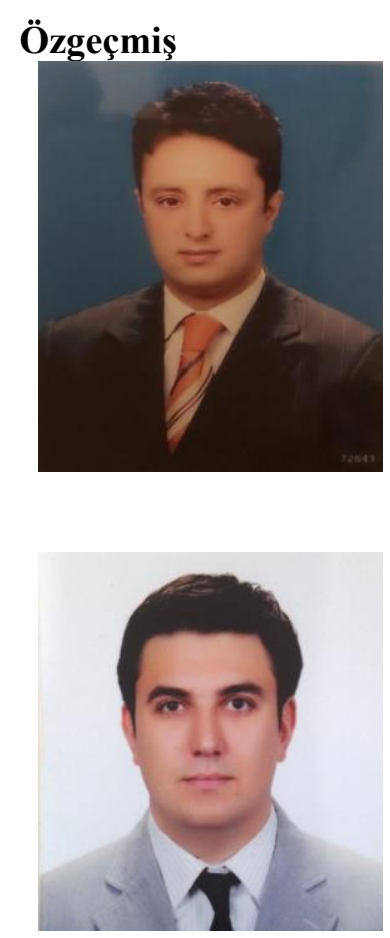

\section{Polat YALINIZ}

1972 yılında Eskişehir'de doğmuştur. Lisans eğitimini Anadolu Üniversitesinde, yüksek lisans ve doktora eğitimini Eskişehir Osmangazi Üniversitesinde tamamlamıştır. Kısa bir özel sektör tecrübesinden sonra akademisyen olarak çalışma hayatına devam etmiştir. Kütahya Dumlupınar Üniversitesi Mühendislik Fakültesi İnşaat Mühendisliği Bölümünde Dr. Öğr. Üyesi olarak görev yapmaktadır. İlgi alanları, Demiryolları, Toprak İşleri, Ulaştırma Mühendisliği konularıdır.

E-Posta: polat.yaliniz@dpu.edu.tr

\section{Sezgin İÇA}

1983 tarihinde İstanbul'da doğmuştur. Lisans eğitimini Orta Doğu Teknik Üniversitesinde, yüksek lisans eğitimini Kütahya Dumlupınar Üniversitesinde tamamlamıştır. Sırasıyla yurtdış1 özel sektör, Kütahya Belediyesi, Ulaştırma, Denizcilik ve Haberleşme Bakanlığı, TCDD Genel Müdürlügü 7. Bölge Müdürlügü ve DSİ 3. Bölge Müdürlüğünde görev almıştır. Kütahya Sağlık Bilimleri Üniversitesi Yapı İşleri ve Teknik Dairesinde çalışmaktadır.

E-Posta: sezgin.ica@ksbu.edu.tr

\section{Beyanlar:}

Bu makalede bilimsel araştırma ve yayın etiğine uyulmuştur.

Tüm yazarların eşit oranda katkısı olmuştur. 